\title{
A Review on Encapsulation of Oils
}

\author{
Zeynep Aksoylu Özbek, Pelin Günç Ergönül² \\ 1,2Manisa Celal Bayar University, Faculty of Engineering, Department of Food Engineering \\ Yunusemre, Manisa, Turkey, +90 2362012271 \\ zeynep.aksoylu@cbu.edu.tr \\ *Corresponding author \\ Recieved: $3^{\text {rd }}$ March 2017 \\ Accepted: 27th May 2017 \\ DOI: $10.18466 /$ cbayarfbe. 313358
}

\begin{abstract}
Heat, oxygen, moisture and light are the main causes of oxidation reactions in lipid containing foods. In particular, lipid oxidation is a major problem for unsaturated lipids. Until recent years, natural or synthetic antioxidants have been widely used in oils to retard oxidative deteriorations. Nowadays, encapsulation of oils like other sensitive materials such as vitamins, colorants, phenolic compounds or probiotic bacteria by various techniques have become increasingly popular as a promising preservation method. On the other hand, encapsulation improves handling properties of oils as well as protecting oils against oxidation. Spray drying is the most preferred encapsulation technique due to its lower operating costs and simplicity. Freeze-drying, coacervation and emulsification are the other well-known encapsulation methods. However, process parameters of these methods have extremely important effect on storage stability of encapsulated oils. As for encapsulated oils by drying, also the characteristics of powder products are greatly influenced by process variables. Many studies have been carried out to optimize process factors for encapsulation of oils with a maximum efficiency. In this review, common practices used for oil encapsulation and the oxidative stability of encapsulated oils are discussed in detail. Furthermore, effects of environmental conditions on storage stability of encapsulated oils during storage are also reviewed.
\end{abstract}

Keywords - Encapsulation, freeze drying, oil, oxidation, spray drying

\section{Introduction}

Encapsulation is the coating of sensitive solid, liquid or gas ingredients such as flavours, enzymes, microorganisms, vitamins, minerals, colorants and lipids, known as core material, with a protective layer which is called wall material [1,2]. The most common wall materials can be divided into three main groups:

1) Carbohydrates

a. Plant based carbohydrates such as maltodextrin, starch, cellulose, gum arabic, mesquite gum, guar gum, galactomannans, cyclodextrin, pectin

b. Marine based carbohydrates such as carrageenan and alginate

c. Microbial or animal based carbohydrates such as xanthan, gellan, dextran, chitosan

2) Proteins

a. Plant based proteins such as soy protein, pea protein, barley protein, zein, gluten

b. Animal based proteins such as casein, whey protein, gelatine

3) Lipids and waxes such as milk fat, phospholipid, beeswax and carnauba wax [3-5].

The selection of suitable wall materials depends on the properties of core material and final capsules [6]. An optimal wall material should have the following characteristics:

a) Be food - grade

b) Be cheap

c) Have low viscosity at high solid contents

d) Have good emulsifying properties 
e) Have good emulsion stability

f) Have the ability of holding core material in its structure without any reactivity during processing or storage

g) Controllable release of core material

h) Protect core material from any environmental conditions, particularly oxygen, humidity and light [6-8].

The powder products obtained by encapsulation are called by different names according to size of particles. These are macrocapsules $(>5000 \mu \mathrm{m})$, microcapsules $(1-5000 \mu \mathrm{m})$ and nanocapsules $(<1 \mu \mathrm{m})$ [9]. The purposes of encapsulation are as follows:

a) Protection of core material from environmental factors (oxygen, temperature, light, moisture, $\mathrm{pH}$ etc.)

b) Controlled release of core materials

c) Masking of undesired odours

d) Improvement of handling and flow properties of core materials [10].

In addition to these, the main aim of encapsulation of oils and lipids is to prevent oxidation and so to extend the shelf-life of these products [11]. Various techniques may be used for encapsulation. These are summarized in Table 1.

Table 1. Particle sizes of capsules produced by different encapsulation methods [12]

\begin{tabular}{|l|c|}
\hline \multicolumn{1}{|c|}{ Encapsulation Technology } & $\begin{array}{c}\text { Particle size of } \\
\text { capsules }(\boldsymbol{\mu m})\end{array}$ \\
\hline Spray drying & $10-400$ \\
\hline Fluid bed coating & $5-5000$ \\
\hline Spray chilling / cooling & $20-200$ \\
\hline Melt injection & $300-2000$ \\
\hline Melt extrusion & $0.2-5000$ \\
\hline Emulsification & $0.2-5000$ \\
\hline Emulsions with multilayers & $10-800$ \\
\hline Coacervation & $200-5000$ \\
\hline $\begin{array}{l}\text { Microspheres produced by } \\
\text { extrusion or dropping }\end{array}$ & $10-1000$ \\
\hline $\begin{array}{l}\text { Microspheres produced by } \\
\text { emulsification }\end{array}$ & $150-8000$ \\
\hline Co-extrusion & $0.001-0.01$ \\
\hline Inclusion complexation
\end{tabular}

\begin{tabular}{|l|c|}
\hline Liposome entrapment & $10-1000$ \\
\hline $\begin{array}{l}\text { Rapid expansion of super- } \\
\text { critical fluids }\end{array}$ & $10-400$ \\
\hline Freeze or vacuum drying & $20-5000$ \\
\hline
\end{tabular}

The selection of proper encapsulation method depends on certain parameters: mean particle size, physicochemical characteristics of core and wall materials, application of encapsulated material, release system of capsules, commercial production capacity and cost [13]. Meanwhile, nanoencapsulation methods are more complicated than the microencapsulation ones [14].

Oils are generally encapsulated to protect their beneficial compounds, to extent shelf - lives of them and to mask unacceptable odours. In this paper, various oil encapsulation techniques and numerous examples will be reviewed.

\section{Spray drying}

One of the oldest and most widely used food encapsulation technique is spray drying [15]. It is cost effective, modifiable depending on encapsulation matrix, compatible with other processing equipment [6]. Moreover, heat - sensitive materials can be processed with negligible damages [16]. Due to these advantages, spray drying is commonly preferred for oil encapsulation. Nonetheless, one should keep in mind that high drying temperatures of spray dryer may trigger oxidation reactions in oils [17].

Formation of stable emulsion is the critical step for encapsulation by spray drying. Insufficient emulsification causes larger droplets and instability of emulsion and so lower encapsulation efficiency [18]. Smaller oil globules are better encased in wall matrix and attractive forces between the globules decrease. Hence, more stable emulsions are obtained $[19,20]$. Likewise, solid content has a direct effect on emulsion droplet size. In other words, when the total solid content of emulsion increases, the sizes of emulsion droplets decrease [21]. This impact may be related to increased emulsion viscosity or sufficient amount of wall materials solution to surround the droplets effectively [22]. However, high viscosity of emulsion is desired to a certain extent because it may lead to 
blockage problems in spray dryer [23]. Processing and atomization of emulsions with viscosities higher than $200 \mathrm{mPa}$ in spray dryer is extremely harder [24]. Gharsallaoui et al. [25] reported that the diameter of initial emulsion droplet should be between $1-100$ $\mu \mathrm{m}$. Larger emulsion droplets may be broken during atomization step of spray drying and this causes high amounts of non - encapsulated surface oils [26]. According to Goula and Adamopoulos [27], as the droplet size of emulsion decreased, the encapsulation efficiency (EE) of pomegranate seed oil increased.

Emulsion droplet size is mainly influenced by emulsion homogenization pressure. Hogan et al. [28] concluded that the volume average diameter of droplets decreased from 0.93 to $0.38 \mu \mathrm{m}$, when the homogenization pressure increased from 10 to $50 \mathrm{MPa}$. Similarly, Holgado et al. [29] obtained smaller and more uniform oil droplets with increased homogenization pressure. Furthermore, Takeungwongtrakul et al. [30] reported that the emulsions prepared with higher homogenizing pressure were more stable during 14 - day storage. In recent years, some homogenizers such as high - intensity ultrasound, microfluidizers or membrane homogenizers are used to produce emulsions having smaller droplets [31]. Silva et al. [32] reported that droplet mean diameter in emulsion ranged between $2.02-2.33 \mu \mathrm{m}$ for only Ultra - Turrax homogenization; while droplet mean diameter ranged between $1.05-1.51 \mu \mathrm{m}$ for high pressure homogenization after Ultra - Turrax. In addition, Tontul and Topuz [33] stated that they obtained flaxseed oil droplets with mean particle size that is onetenth of the size of flaxseed oil droplets produced by Carneiro et al. [34]. The main reason of this dramatic difference is just emulsification process. Tontul and Topuz [33] preferred ultrasonic emulsification, whereas Carneiro et al. [34] used conventional emulsification. Emulsification method also influences encapsulation efficiency and size of particles in oil encapsulation by spray drying. According to Koç et al. [35] ultrasonic homogenization caused to lower EE of extra virgin olive oil and smaller particles than rotor - stator homogenizator.

On the other side, the composition of emulsion is another key player for emulsion stability. Therefore, wall materials should have emulsifying properties. As mentioned before, carbohydrates, proteins or combination of these are generally used as wall materials for oil encapsulation. The major functions of carbohydrates in encapsulation are promotion of drying properties of wall matrix by increasing dry crust formation over the drying droplets [36]. Minemoto et al. [37] found that the emulsions prepared with gum arabic is more stable than the emulsions with maltodextrin. They clarified this situation by the chemical structures of these wall materials. Gum arabic acts as an emulsifier due to its proteinaceous matter [38]. However, maltodextrin, a digestion product of starch, is just composed of D - glucose units [39]. In addition, increase in dextrose equivalent (DE) of carbohydrates has protective effect against oxidation [36]. This is because EE increases, as DE values of carbohydrates increase. In a study carried out by Hogan et al. [40] EE of soy oil increased from $0 \%$ to $92 \%$, when maize starch with DE 50 was used instead of maize starch with DE 0.

To improve emulsifying characteristics, generally, carbohydrates are used with proteins in oil encapsulation [41]. Nevertheless, the stability of emulsion stabilized by proteins is influenced by $\mathrm{pH}$ of emulsion. Specifically, the emulsifying capacity of proteins is minimum at their isoelectric point [42]. Additionally, in some cases, antagonistic effects may be observed between proteins and carbohydrates for EE. Tontul and Topuz [43] found that sodium caseinate and gum arabic combination had the lowest EE for flaxseed oil, whereas whey protein concentrate increased the EE of gum arabic. Similarly, Goyal et al. [44] reported that whey protein concentrate - lactose combination as wall material resulted in higher encapsulation efficiency of flaxseed oil than sodium caseinate - lactose combination. The authors explained this by the formation of more Maillard reaction products in whey protein concentrate mixtures as a result of higher lysine content of whey protein concentrate [44]. Protein - carbohydrate compounds occurred in Maillard reaction have better emulsifying characteristics than proteins [45].

In general, protection of oils against oxidation is closely related to EE. Higher efficiency leads to better protection. In addition to this, the type of wall mate- 
rial is also important. Minemoto et al. [37] reported that oxidation of linoleic acid encapsulated with gum arabic was slower than encapsulated with maltodextrins. The authors stated that smaller droplet size of emulsions containing gum arabic caused a decrease in the rate of oxidation reactions [37]. Although its lower EE, flaxseed oil encapsulated with whey protein concentrate had lower peroxide values than those encapsulated with gum arabic [46]. A similar trend was also observed by Gallardo et al. [47]. This can be a result of antioxidant activity of whey proteins [48]. Nonetheless, it should be kept in mind that, when low molecular weight carbohydrates such as maltodextrins or saccharose are used in microencapsulation, they may cause caking, structural collapsing and recrystallization of amorphous carbohydrate matrix during storage [49]. Caking and recrystallization lead to leakage of core material from microcapsules [50]. Microcapsules should be stored at low temperatures (below $T_{8}$ of powders) under controlled relative humidity $(\mathrm{RH})$ conditions to prevent caking [51].

The size, shape and smoothness of spray - dried particles are affected by dry matter content of emulsion. Turchiuli et al. [52] found that average diameter of particles increased from 18 to $85 \mu \mathrm{m}$, when total solid content of emulsion increased from $30 \%$ to $50 \%$. Moreover, Sahin-Nadeem and Özen [53] determined that incorporation of whey proteins to carbohydrate based wall material mixture increased the smoothness of particles' surfaces for pomegranate seed oil encapsulation. On the contrary, Botrel et al. [54] found that partial substitution of whey protein isolate by inulin improved the viscoelastic characteristics of wall matrix and these particles, which contained fish oil as core material, displayed smoother surfaces. However, in general, microcapsules including polysaccharide based wall materials have remarkable surface dents, while whey protein based particles display smoother surfaces [55]. Microcapsules with less porosity have fewer spaces among particles that hinder oxidation reactions [56]. Nijdam and Langrish [57] proposed high temperatures of spray dryer cause melting of fat found within the walls and this melted fat moves through the pores. As a result, in general, fat/oil is concentrated close to the surface of powders. Another key element affect- ing microcapsule's morphology is inlet temperature of spray dryer. According to Wang et al. [58] amorphous microcapsules were produced, when the inlet temperature of spray dryer was $180^{\circ} \mathrm{C}$. On the contrary, spherical microcapsules with more homogenous sizes were obtained, when the temperature decreased to $150^{\circ} \mathrm{C}$. Spray drying of emulsions at lower temperatures than $150^{\circ} \mathrm{C}$ caused the insufficient drying of microparticles [58]. Eventually, adequately dried microcapsules having spherical outer surfaces without ruptures are critical for reduced permeability of gases and better protection of core material [59].

Water solubility index (WSI) is a significant criterion for dried powder products to enhance their integration to other foods. It has been proved that powders in crystalline state have lower interaction with water, while amorphous solids contain polar energetic sites having hydrogen bonding capacity with water molecules [60]. In a study dealing with encapsulation of annatto seed oil with whey protein isolate or modified starch by spray drying or freeze drying techniques, it was reported that all microparticles, independent from the type of wall material and drying method used, exhibited amorphous state [61]. Amorphous powders have higher solubility and are more hygroscopic [54]. This parameter is also affected by concentration of oil, in other words "oil load". As the amount of oil increases, the hydrophobicity of powder product increases. However, this leads to decrease of interaction with water and so, the solubility decreases [62]. On the other side, small and polar wall materials with hydrophilic properties such as inulin improve the solubility of spray dried oil capsules [63].

Moisture content and water activity (aw) are crucial factors for storage stability of powder products. The moisture contents of spray dried oil capsules are close to the maximum moisture range, $3-4 \%$, for many powder food products [64]. Roccia et al. [65] suggested that drying air inlet temperature, atomization air flow rate and pump setting were the main factors on the moisture content of spray dried powders. Furthermore, Laohasongkram et al. [66] reported that an increase in feeding rate caused an increase in moisture contents of spray dried Macadamia oil 
powders. On the other hand, homogenization pressure also alters moisture content and aw of encapsulated powders. Ixtaina et al. [67] determined that microcapsules with higher moisture content and $\mathrm{a}_{\mathrm{w}}$ were obtained when homogenization pressure decreased from 600 bar to 400 bar. Lipid oxidation is usually minimum at aw range of $0.20-0.40$ for many food products [68]. Additionally, Carvalho et al. [69] concluded that spray - dried coffee oil microparticles having aw below or equal to 0.20 exhibited lower oxidative stability.

Temperature and glass transition temperature $\left(T_{8}\right)$ are the other key elements, which may influence oxidation of encapsulated lipids during processing or storage [70]. For instance, oxidation of encapsulated coffee oil accelerated at $60^{\circ} \mathrm{C}$ compared to $40^{\circ} \mathrm{C}$ [21]. Correspondingly, Stapelfeldt et al. [71] observed a tenfold increase in oxidation products when storage temperature increased by $10^{\circ} \mathrm{C}$. On the other side, Aghbashlo et al. [72] determined that wall materials with lower $T_{g}$ increased encapsulation efficiency of spray dried fish oil capsules by means of stimulating formation of crust. To the best of our knowledge, improved encapsulation efficiency contributes to increased oxidative stability of encapsulated oils. Glassy state of microcapsules, which occurs during drying of food matrices containing protein or carbohydrates, partially preserve the microcapsule against lipid oxidation [73]. To maintain the glassy state of wall materials, spray drying should be carried out below $T_{g}$ of wall materials [20]. Above $T_{g}$ amorphous materials start to crystallize and crystalline substances hold less water than its amorphous state. In a closed system, this leads to increase of $a_{w}$ [74]. As a consequence, peroxide values of encapsulated oils within wall matrices containing lower $T_{g}$ increase rapidly and agglomeration of microparticles occurs [75]. Also, RH influences the oxidation rate of spray dried oil powders [76]. Fang et al. [77] reported that linoleic acid encapsulated by spray drying oxidized rapidly at higher $\mathrm{RH}$. Similarly, lipid oxidation of encapsulated fish oil increased at higher RH conditions due to crystallization of trehalose, which was used as wall material [49].

A great number of published works dealt with extensively oxidative changes in encapsulated oils during processing and storage. It is believed that oxidation reactions begin in the homogenization step [78]. Due to breakdown of droplets and shear forces during homogenization, oxygen is easily distributed within emulsion and hence, the rate of oxidation increases [79]. Aghbashlo et al. [80] reported higher peroxide values in spray dried encapsulated fish oils as the drying air temperature, aspirator and peristaltic pump rates increased. Wang et al. [81] explained the reason of high peroxide values of encapsulated fish oil at the early stage of storage by rapid film formation of emulsions with high protein content. According to authors, probably the evaporation resistance was increased by film and this led to rapid temperature rise of particles during drying. Consequently, peroxides formed due to high temperature of particles [81]. In contrast to results obtained by Wang et al. [81], Martinez et al. [82] reported that the amount of lipid oxidation products in encapsulated walnut and chia oils did not increase just after spray drying. However, while encapsulation by spray drying protected the walnut oil from oxidative deterioration, it accelerated oxidative damage of encapsulated chia oil. The authors attributed this difference to different unsaturation degree of these oils [82]. Oxidation of encapsulated oil during storage may damage other components of oils such as carotenes and cholesterol as well $[83,84]$.

Oxidation reactions occur in non-encapsulated (surface) oil [85]. Ahn et al. [86] reported peroxide value (PV) of spray - dried microencapsulated sunflower oil with lower EE (70.20\%) was $15.20 \mathrm{meq} / \mathrm{kg}$, whereas it was $8.70 \mathrm{meq} / \mathrm{kg}$ for microencapsulated sunflower oil with the highest EE (96.60\%). PVs of oil capsules are negatively affected by any increase in aqueous phase of oil-in-water emulsion [87]. Oxidation reactions cause formation of compounds, which leads to off - flavour in foods. Kolanowski et al. [88] concluded that microencapsulation by spray drying stimulated undesirable sensory changes in fish oil with the existence of oxygen. Keogh and O'Kennedy [89] showed that sour off - flavour occurred earlier in spray - dried milk fat powders with higher surface fat $(49.40 \%)$ compared to milk fat powders with lower surface fat. Same authors, in an another study, revealed that development of off-flavour in spray dried fish oil microcapsules increased as homogeni- 
zation pressure of emulsion increased [90]. To prevent sensory deteriorations in encapsulated oils due to oxidation, lipophilic antioxidants such as $\alpha-$ tocopherol can be used effectively [91]. In addition to oxidation, surface oil may favour caking or agglomeration of microparticles [92].

In summary, spray drying is a cost effective oil encapsulation method. However, process conditions should be optimized to prevent undesirable changes, such as oxidation, in oil. Some antioxidants may be used for this purpose.

\section{Freeze drying}

Freeze drying, which is more commonly known as lyophilisation, is composed of three principal stages. Firstly, the product is frozen and then, ice is sublimed from the solid state under vacuum (sublimation step). Finally, unfrozen (bound) water is removed by evaporation under reduced pressure (desorption step) [93,94]. The advantages of freeze drying in terms of oil encapsulation can be outlined as follows:

a) Decreased deterioration of heat - sensitive compounds (unsaturated fatty acids, tocopherols etc.)

b) Controllable moisture of end products

c) Easier reconstitution of freeze dried oil microcapsules [95].

Despite of these advantages, high operation costs, long processing time and open porous structure of the end product limit the application of this technology in food industry [96]. Furthermore, encapsulation efficiency by freeze drying is not as high as encapsulation by spray drying.

Freezing rate in an important parameter in freeze dried oil capsules. Heinzelmann et al. [97] reported that slow freezing rate $\left(\right.$ at $\left.-20^{\circ} \mathrm{C}\right)$ increased the shelflife of fish oil microcapsules. Similarly, in an another study, Heinzelmann et al. [98] determined that slowly-frozen fish oil microcapsules had higher microencapsulation efficiency compared to fast-frozen samples. Lower cooling temperatures cause movement of dispersed oil droplets to the continuous phase and so, these oil droplets aggregates [99]. Encapsulation efficiency is negatively affected by emulsion breakdown.

Encapsulation efficiency, which influences the oxidative stability of encapsulated oils, partially depends on wall matrix components. For instance, $\gamma-$ cyclodextrin was found to be more effective compared to $\beta$-cyclodextrin in terms of improving stability of emulsion and so, encapsulation efficiency [100]. Differently from this, Koç et al. [101] stated that, although its lower encapsulation efficiency, freeze dried fish oil capsules containing pullulan had better oxidative stability than lactose containing capsules due to pullulan's capability of forming strong films with minimum oxygen permeability. Silva and Meireles [102] reported that encapsulation efficiency of annatto seed oil decreased as the degree of polymerization of inulin, the wall material, decreased. Similarly, Zhang et al. [103] determined that encapsulation efficiency of freeze dried fish oil decreased when degree of hydrolysis of soy protein isolate - maltodextrin conjugates increased. This may be due to insufficient strength of wall matrix with shorter chain length to cover the oil completely. Parallel results were obtained by Karaca et al. [104], who reported lower EE in freeze dried flaxseed oil encapsulated with maltodextrin with higher DE than maltodextrin with lower DE. On the contrary to these studies, Turasan et al. [105] showed that rosemary essential oil capsules containing maltodextrin with low DE $(4-7)$ as wall material had higher storage stability due to its higher $T_{8}$ compared to capsules with higher DE $(13-17)$ maltodextrin.$T_{g}$ of food matrices can be increased by addition of compounds having high molecular weight [106]. This might explain why protein based wall materials protect the oil capsules from oxidation better than carbohydrate based wall materials although they have lower encapsulation efficiency $[107,108]$.

As in the case of spray drying, $T_{g}$ is an influential aspect for freeze dried products. Imamura et al. [109] declared that a great majority of linoleic acid methyl ester were lost in the early step of freeze drying, in which sugar units were entirely hydrated in the amorphous phase between ice crystals. After drying, controlling of humidity and temperature of storage environment is extremely significant for mainte- 
nance of quality of freeze dried products. In dried product, collapsing appears in case of change in moisture content or increase of temperature due to transformation of glassy amorphous state of encapsulated oil into rubbery state at $T_{g}$ [110]. Occurrence of collapse may trigger the oxidation by increasing the exposure area of oil to oxygen [111]. Owing to extremely low drying temperatures used during freeze drying, the temperature of dried product never surpasses its $T_{g}$ and hence, oil capsules keep their glassy state throughout drying and storage [112]. Freeze dried microparticles are generally have porous and irregular structures. On the other hand, porosity of matrix contributes to oxygen diffusion through microcapsules, and this may affect the storage life of product [61]. The holes observed via scanning electron microscope in the lyophilized products were associated with water that was removed during lyophilisation [113].

Oxidation stability of encapsulated oils is also altered by RH. Oxidation of surface oil decelerated when RH increased from $0 \%$ to $32 \%$ [114]. They attributed this result to bonding of hydrogen, a fraction of hydroperoxides that are generated in propagation phase of oxidation, by moisture. So, further oxidation reactions, in which hydroperoxides are used as substrates, are prevented. However, Minemoto et al. [115] explained this situation by hydrophobic character of oxygen. Under intermediate $\mathrm{RH}$ conditions, water is adsorbed by two or more layers of wall material and the diffusion of hydrophobic oxygen through these layers becomes difficult. On the other side, Velasco et al. [116] suggested that surface oil oxidizes likewise bulk oil (continuous phase), while encapsulated oil follows a pattern similar to mixtures having different oxidation levels. This variation is due to different oxidation degrees of oil droplets encased in a wall matrix [117].

Antioxidants can be added to emulsions to retard lipid oxidation. Velasco et al. [118] reported that polar antioxidants, in other words hydrophilic antioxidants, were less effective in oil-in-water emulsion system than lipophilic antioxidants. Since polar antioxidants are particularly situated in the aqueous phase of emulsions, they cannot preserve oil phase from oxidation. Similar to this manner, lipophilic radicals boosted the oxidation of freeze dried encapsulated rapeseed oil, whereas hydrophilic radicals were found to be ineffective [119].

In conclusion, in addition to studies mentioned above, Avramenko et al. [120], Dzondo-Gadet et al. [121] and Minemoto et al. [122] also suggested the protective effect of freeze drying encapsulation process on lipid oxidation.

\section{Coacervation}

The phase separation of the liquid phase of an aqueous solution of hydrocolloids under controlled conditions (adjusting by changing $\mathrm{pH}$ or temperature of solution and/or adding micro ions) and deposition of the resulting phase, known as coacervate, on the surface of core material is called "coacervation" [123]. The liquid - liquid phase separation is named as "coacervation", whereas solid - liquid phase separation is named as "precipitation" [124]. The fundamental stages of coacervation are as follows: 1) core material is emulsified within an aqueous solution consisted of two polymers at above gelling temperature of protein and above isoelectric $\mathrm{pH}$ of protein; 2) immiscible phases are formed; 3) liquid polymer(s) is/are deposited around the core material; 4) microcapsules are stabilized via cross - linking agents various drying processes such as spray drying or freeze drying $[125,126]$.

There exist two types of coacervation: simple coacervation that includes only one polymer and complex coacervation, which consists of two immiscible liquid phases with oppositely charged ions. Complex coacervates are generally preferred for encapsulation of bioactive food components [12,127]. Principally, a protein fragment such as gelatine or whey protein and a carbohydrate fragment such as cellulose, gum arabic, chitosan or carrageenan are used as biopolymers in coacervation technique [128]. The formation of protein/carbohydrate complexes and coacervates depends on many factors: ionic strength, $\mathrm{pH}$ and temperature of solution; molecular weights, total concentration and charge density of biopolymers; ratio of protein to carbohydrate; pressure and stirring $[129,130]$. Mononuclear or multinuclear capsules can be produced by coacervation. In mononuclear capsule, core material is enclosed by coacervates; 
while multinuclear capsule involves emulsified two separate cores [131]. Mononuclear capsule is a reservoir type system and delivers core material entirely even when only a part of wall material is damaged. Contrastingly, multinuclear capsule has a matrix type system and delivers the core material slowly even when wall material is fully damaged $[132,133]$. Due to these reasons, formation of multinuclear capsules is desired to extend the shelf - life of sensitive food components. The superiority of coacervation over the other oil encapsulation techniques is to produce powders with less surface oil even at higher oil (core material) loading levels [134].

Studies in the literature revealed that concentration and composition of wall materials, stirring speed and $\mathrm{pH}$ should be optimized to obtain spherical multinuclear capsules [135-137]. However, undoubtedly, pH is the most important factor in coacervation method. Suitable $\mathrm{pH}$ range depends on the types and the charges of biopolymers. While Weinbreck et al. [138] determined that a smooth whey protein - gum arabic coacervate layer formed at $\mathrm{pH} 4, \mathrm{pH} 5$ was selected as the best operation point for chitosan - gelatine (B) coacervates [139]. Secondly, stirring rate and homogenization speed play an important role. Aziz et al. [140] reported that a reduction in dimensions of microcapsules and an increase in the ratio of mononuclear microcapsules occurred, when the stirring speed increased. The main reason of increase in the amount of mononuclear capsules is the inadequate contact time between oil droplets due to high turbulence level caused by higher stirring rate [141]. If there is enough contact time, oil droplets can approach each other and two or more oil droplets may be combined in one capsule (multinuclear type). All of these parameters should be adjusted for coacervates with required characteristics.

Microencapsulation by coacervation, like the other techniques, contributes to the protection of oils against undesirable changes during storage. Throughout a 40-day storage in cold water, only $7 \%$ of peppermint oil was delivered from coacervate microcapsules, which consisted of gelatine and gum arabic [142]. On the other hand, Wang et al. [143] obtained freeze dried tuna oil capsules with extremely high EE of $98.56 \%$ by applying gelatine - sodium hexametaphosphate coacervates. These tuna oil microcapsules displayed more than 2-fold oxidation stability compared to bulk oil. Similar results were received by Siow and Ong [144], Martins [145] and Eratte et al. [146].

To the best of our knowledge, up to today, lemon and orange oil [138]; fish oil [147-149]; peppermint oil [150,151]; thyme oil [152]; sunflower oil [153]; cinnamon oil [154]; coriander oil [155]; lavender oil [156]; coffee oil [157]; flaxseed oil [158], olive oil [159]; palm oil [160]; citronella oil [139] and kiwi fruit seed oil [161] were successfully microencapsulated by coacervation technique. However, it should be noted that the composition of every oil substantially varies and this difference majorly affects the efficiency of coacervation method [162,163].

\section{Other Methods}

In addition to common microencapsulation techniques explained above, there are limited oil encapsulation studies including single layer emulsions [164,165]; multilayer emulsions [166,167]; molecular inclusion [168-170]; use of particles from gassaturated solution (PGSS) process [171]; use of macroscopic beads [172] and miniemulsification-solvent evaporation technique [173]. In particular, new and expensive methods are evaluated to preserve volatile compounds of essential oils.

\section{Conclusion}

Various encapsulation techniques, mainly spray drying, freeze drying and coacervation, have been successfully utilized to preserve oils from oxidative deterioration. Mostly, the priority of encapsulation studies is to increase EE of oils. However, EE is affected by a combination of numerous process factors. These factors include equipment parameters, characteristics of wall matrix and oils' properties. The knowledge about impacts of all of these variables on encapsulation of oils has been increased in recent years. Nonetheless, the adaptation of these laboratory based results into industrial scale production of oil capsules has not been made. Further studies should concentrate on optimization of industrial scale encapsulation processes. Moreover, novel wall materials and encapsulation techniques should be investi- 
gated to obtain oil capsules with higher EE and lower production costs.

\section{References}

[1] Risch, S.J.; Encapsulation: Overview of Uses and Techniques. In Encapsulation and Controlled Release of Food Ingredients; Risch S.J., Reineccius G.A., Eds.; American Chemical Society: Washington, DC, 1995; pp. 2 7.

[2] McNamee, B.F.; O'Riordan, E.D.; O'Sullivan, M. Emulsification and Microencapsulation Properties of Gum Arabic, Journal of Agricultural and Food Chemistry, 1998; 46(11), 4551-4555.

[3] Augustin, M.A.; Sanguansri, L.; Challenges in Developing Delivery Systems for Food Additives, Nutraceuticals and Dietary Supplements. In Encapsulation Technologies and Delivery Systems for Food Ingredients and Nutraceuticals; Garti, N., McClements, D.J., Eds.; Elsevier: Cornwall, UK, 2012; pp. 19-48.

[4] Lakkis, J.M.; Introduction. In Encapsulation and Controlled Release Technologies in Food Systems; Lakkis J.M., Ed.; Blackwell Publishing Ltd: Iowa, USA; 2007; pp. $1-11$.

[5] Wandrey, C.; Bartkowiak, A.; Harding, S.E.; Materials for Encapsulation. In Encapsulation Technologies for Active Food Ingredients and Food Processing; Zuidam, N.J., Nedović, V.A., Eds.; Springer-Verlag New York: New York, 2010; pp. 31-100.

[6] Desai, K.G.H.; Park, H.J. Recent Developments in Microencapsulation of Food Ingredients, Drying Technology, 2005; 23(7), 1361-1394.

[7] Shahidi, F.; Han, X-Q. Encapsulation of Food Ingredients, Critical Reviews in Food Science and Nutrition, 1993; 33(6), 501-547.

[8] Nedović, V.; Kalušević, A.; Manojlović, V.; Petrović, T.; Bugarski, B.; Encapsulation Systems in the Food Industry. In Advances in Food Process Engineering Research and Applications; Yanniotis, S., Taoukis, P., Stoforos, N.G., Karathanos, V.T., Eds.; Springer Science+Business Media: New York, 2013; pp. 229-253.

[9] King, A.H.; Encapsulation of Food Ingredients A Review of Available Technology, Focusing on Hydrocolloids. In Encapsulation and Controlled Release of Food Ingredients; Risch, S.J., Reineccius, G.A., Eds.;
American Chemical Society: Washington, DC, 1995; pp. 26-39.

[10] Fang, Z.; Bhandari, B.; Encapsulation Techniques for Food Ingredient Systems. In Food Materials Science and Engineering; Bhandari, B., Roos, Y.H., Eds.; WileyBlackwell: West Sussex, UK, 2012; pp. 320-348.

[11] Karaca, A.C.; Low, N.H.; Nickerson, M.T. Potential Use of Plant Proteins in The Microencapsulation of Lipophilic Materials in Foods, Trends in Food Science and Technology, 2015; 42(1), 5-12.

[12] Zuidam, N.J.; Shimoni, E.; Overview of Microencapsulates for Use in Food Products or Processes and Methods to Make Them. In Encapsulation Technologies for Active Food Ingredients and Food Processing; Zuidam, N.J., Nedovic,' V.A., Eds.; Springer New York: New York, 2010; pp. 3-29.

[13] I Ré, M. Microencapsulation By Spray Drying. Drying Technology, 1998; 16(6), 1195-1236.

[14] Kwak, H-S.; Overview of Nano- and Microencapsulation for Foods. In Nano- and Microencapsulation for Foods; Kwak, H-S., Ed.; WileyBlackwell: West Sussex, UK, 2014; pp. 1-14.

[15] Balassa, L.L.; Fanger, G.O.; Wurzburg, O.B. Microencapsulation in the Food Industry, CRC Critical Reviews in Food Technology, 1971; 2(2), 245-265.

[16] Bhandari, B.R.; Patel, K.C.; Chen, X.D. Spray Drying of Food Materials - Process and Product Characteristics. In Drying Technologies in Food Processing; Chen, X.D., Mujumdar, A.S., Eds.; Blackwell Publishing Ltd: Singapore, 2008; pp. 113-159.

[17] Kolanowski, W.; Ziolkowski, M.; Weißbrodt, J.; Kunz, B.; Laufenberg, G. Microencapsulation of Fish Oil by Spray Drying--Impact on Oxidative Stability. Part 1, European Food Research and Technology, 2006; 222(3-4), 336-342.

[18] Danviriyakul, S.; McClements, D.J.; Decker, E.; Nawar, W.W.; Chinachoti, P. Physical Stability of Spray-Dried Milk Fat Emulsion as Affected by Emulsifiers and Processing Conditions, Journal of Food Science, 2002; 67(6), 2183-2189.

[19] Jafari, S.M.; Assadpoor, E.; Bhandari, B.; He, Y. Nanoparticle Encapsulation of Fish Oil by Spray Drying, Food Research International, 2008; 41(2), 172-183.

[20] Anandharamakrishnan, C.; Ishwarya, S.P., Spray 
Drying Techniques for Food Ingredient Encapsulation; John Wiley \& Sons Ltd: Chichester, UK, 2015; pp. 312.

[21] Frascareli, E.C.; Silva, V.M.; Tonon, R.V.; Hubinger, M.D. Effect of Process Conditions on the Microencapsulation of Coffee Oil by Spray Drying, Food and Bioproducts Processing, 2012; 90(3), 413-424.

[22] Kha, T.C.; Nguyen, M.H.; Roach, P.D.; Stathopoulos, C.E. Microencapsulation of Gac Oil by Spray Drying: Optimization of Wall Material Concentration and Oil Load Using Response Surface Methodology, Drying Technology, 2014; 32(4), 385-397.

[23] Li, J.; Xiong, S.; Wang, F.; Regenstein, J.M.; Liu, R. Optimization of Microencapsulation of Fish Oil with Gum Arabic/Casein/Beta-Cyclodextrin Mixtures by Spray Drying, Journal of Food Science, 2015; 80(7), C1445-C1452.

[24] Augustin, M.A.; Bhail, S.; Cheng, L.J.; Shen, Z.; Øiseth, S.; Sanguansri, L. Use of Whole Buttermilk for Microencapsulation of Omega-3 Oils, Journal of Functional Foods, 2015; 19(B), 859-867.

[25]Gharsallaoui, A.; Roudaut, G.; Chambin, O.; Voilley, A.; Saurel, R. Applications of Spray-Drying in Microencapsulation of Food Ingredients: An Overview, Food Research International, 2007; 40(9), 1107-1121.

[26] Jafari, S.M.; Assadpoor, E.; He, Y.; Bhandari, B. Encapsulation Efficiency of Food Flavours and Oils during Spray Drying, Drying Technology, 2008; 26(7), 816-835.

[27] Goula, A.M.; Adamopoulos, K.G. A Method for Pomegranate Seed Application in Food Industries: Seed Oil Encapsulation, Food and Bioproducts Processing, 2012; 90(4), 639-652.

[28] Hogan, S.A.; McNamee, B.F.; O’Riordan, E.D.; O'Sullivan, M. Microencapsulating Properties of Whey Protein Concentrate 75, Journal of Food Science, 2001; 66(5), 675-680.

[29] Holgado, F.; Márquez-Ruiz, G.; Dobarganes, C., Velasco, J. Influence of Homogenisation Conditions and Drying Method on Physicochemical Properties of Dehydrated Emulsions Containing Different Solid Components, International Journal of Food Science and Technology, 2013; 48(7), 1498-1508.

[30] Takeungwongtrakul, S.; Benjakul, S.; Aran, H-K. Micro-encapsulation of Pacific White Shrimp Oil as Affected by Emulsification Condition, Food Science and
Human Wellness, 2014; 3(3-4), 175-182.

[31] McClements, D.J., Food Emulsions Principles, Practices, and Techniques - 2nd ed.; CRC Press: Boca Raton, FL, 2004; pp. 632.

[32] Silva, V.M.; Vieira, G.S.; Hubinger, M.D. Influence of Different Combinations of Wall Materials and Homogenisation Pressure on the Microencapsulation of Green Coffee Oil by Spray Drying, Food Research International, 2014; 61, 132-143.

[33] Tontul, I.; Topuz, A. Influence of Emulsion Composition and Ultrasonication Time on Flaxseed Oil Powder Properties, Powder Technology, 2014; 264, 54-60.

[34] Carneiro, H.C.F.; Tonon, R.V.; Grosso, C.R.F.; Hubinger, M.D. Encapsulation Efficiency and Oxidative Stability of Flaxseed Oil Microencapsulated by Spray Drying Using Different Combinations of Wall Materials, Journal of Food Engineering, 2013; 115(4), 443-451.

[35] Koç, M.; Güngör, Ö.; Zungur, A.; Yalçın, B.; Selek, İ.; Ertekin, F.K. Microencapsulation of Extra Virgin Olive Oil by Spray Drying: Effect of Wall Materials Composition, Process Conditions, and Emulsification Method, Food and Bioprocess Technology, 2015; 8(2), 301-318.

[36] Kagami, Y.; Sugimura, S.; Fujishima, N.; Matsuda, K.; Kometani, T.; Matsumura, Y. Oxidative Stability, Structure, and Physical Characteristics of Microcapsules Formed by Spray Drying of Fish Oil with Protein and Dextrin Wall Materials, Journal of Food Science, 2003; 68(7), 2248-2255.

[37] Minemoto, Y.; Hakamata, K., Adachi, S.; Matsuno, R. Oxidation of Linoleic Acid Encapsulated with Gum Arabic or Maltodextrin by Spray-Drying, Journal of Microencapsulation, 2002; 19(2), 181-189.

[38] Williams, P.A.; Phillips, G.O.; Gum Arabic. In Handbook of Hydrocolloids; Phillips, G.O., Williams, P.A., Eds.; Woodhead Publishing Limited: Cambridge, UK, 2000; pp. 155-168.

[39] Chronakis, I.S. On the Molecular Characteristics, Compositional Properties, and Structural-Functional Mechanisms of Maltodextrins: A Review, Critical Reviews in Food Science and Nutrition, 1998; 38(7); 599-637.

[40] Hogan, S.A.; McNamee, B.F.; O'Riordan, E.D.; O'Sullivan, M. Emulsification and Microencapsulation Properties of Sodium Caseinate/Carbohydrate Blends, International Dairy Journal, 2001; 11(3), 137-144. 
[41] Nesterenko, A.; Alric, I.; Silvestre, F.; Durrieu, V. Vegetable Proteins in Microencapsulation: A Review of Recent Interventions and Their Effectiveness, Industrial Crops and Products, 2013; 42(1), 469-479.

[42] Huynh, T.V.; Caffin, N.; Dykes, G.A.; Bhandari, B. Optimization of the Microencapsulation of Lemon Myrtle Oil Using Response Surface Methodology, Drying Technology, 2008;26(3), 357-368.

[43] Tontul, I.; Topuz, A. Mixture Design Approach in Wall Material Selection and Evaluation of Ultrasonic Emulsification in Flaxseed Oil Microencapsulation, Drying Technology, 2013; 31(12), 1362-1373.

[44] Goyal, A.; Sharma, V.; Sihag, M.K.; Tomar, S.K.; Arora, S.; Sabikhi, L. Development and Physico-Chemical Characterization of Microencapsulated Flaxseed Oil Powder: A Functional Ingredient for Omega-3 Fortification, Powder Technology, 2015; 286, 527-537.

[45] Augustin, M.A.; Sanguansri, L.; Bode, O. Maillard Reaction Products as Encapsulants for Fish Oil Powders, Journal of Food Science, 2006;71(2), E25-E32.

[46] Tonon, R.V.; Pedro, R.B.; Grosso, C.R.F.; Hubinger, M.D. Microencapsulation of Flaxseed Oil by Spray Drying: Effect of Oil Load and Type of Wall Material, Drying Technology, 2012; 30(13), 1491-1501.

[47] Gallardo, G.; Guida, L.; Martinez, V.; López, M.C.; Bernhardt, D.; Blasco, R. Microencapsulation of Linseed Oil by Spray Drying for Functional Food Application, Food Research International, 2013; 52(2), 473-482.

[48] Tong, L.M.; Sasaki, S.; McClements, D.J.; Decker, E.A. Mechanisms of the Antioxidant Activity of A High Molecular Weight Fraction of Whey, Jorunal of Agricultural and Food Chemistry, 2000; 48(5), 1473-1478.

[49] Drusch, S.; Serfert, Y.; Van Den Heuvel, A.; Schwarz, K. Physicochemical Characterization and Oxidative Stability of Fish Oil Encapsulated in an Amorphous Matrix Containing Trehalose, Food Research International, 2006; 39(7), 807-815.

[50] Domian, E.; Brynda-Kopytowska, A.; Cenkier, J.; Świrydow, E. Selected Properties of Microencapsulated Oil Powders with Commercial Preparations of Maize OSA Starch and Trehalose, Journal of Food Engineering, 2015; $152,72-84$.
[51] Aguilera, J.M.; del Valle, J.M.; Karel, M. Caking Phenomena in Amorphous Food Powders, Trends in Food Science and Technology, 1995; 6(5), 149-155.

[52] Turchiuli, C.; Fuchs, M.; Bohin, M.; Cuvelier, M.E.; Ordonnaud, C.; Peyrat-Maillard, M.N. Oil Encapsulation by Spray Drying and Fluidised Bed Agglomeration, Innovative Food Science and Emerging Technologies, 2005; 6(1), 29-35.

[53] Sahin-Nadeem, H.; Özen, M.A. Physical Properties and Fatty Acid Composition of Pomegranate Seed Oil Microcapsules Prepared by Using Starch Derivatives/Whey Protein Blends, European Journal of Lipid Science and Technology, 2014; 116(7), 847-856.

[54] Botrel, D.A.; de Barros Fernandes, R.V.; Borges, S.V.; Yoshida, M.I. Influence of Wall Matrix Systems on the Properties of Spray-Dried Microparticles Containing Fish Oil, Food Research International, 2014; 62, 344-352.

[55] Sheu, T.; Rosenberg, M. Microstructure of Microcapsules Consisting of Whey Proteins and Carbohydrates, Journal of Food Science, 1998; 63(3), 491494.

[56] Santana, A.A.; de Oliveira, R.A.; Pinedo, A.A.; Kurozawa, L.E.; Park, K.J. Microencapsulation of Babassu Coconut Milk, Food Science and Technology (Campinas), 2013; 33(4), 737-744.

[57] Nijdam, J.J.; Langrish, T.A.G. An Investigation of Milk Powders Produced by A Laboratory-Scale Spray Dryer, Drying Technology, 2005; 23(5), 1043-1056.

[58] Wang, R.; Tian, Z.; Chen, L. A Novel Process for Microencapsulation of Fish Oil with Barley Protein, Food Research International, 2011; 44(9), 2735-2741.

[59] Tonon, R.V.; Grosso, C.R.F.; Hubinger, M.D. Influence of Emulsion Composition and Inlet Air Temperature on the Microencapsulation of Flaxseed Oil by Spray Drying, Food Research International, 2011; 44(1), 282-289.

[60] Puri, V.; Dantuluri, A.K.; Kumar, M.; Karar, N.; Bansal, A.K. Wettability and Surface Chemistry of Crystalline and Amorphous Forms of A Poorly Water Soluble Drug, European Journal of Pharmaceutical Sciences, 2010; 40(2), 84-93.

[61] Silva, E.K.; Azevedo, V.M.; Cunha, R.L.; Hubinger, M.D.; Meireles, M.A.A. Ultrasound-Assisted Encapsulation of Annatto Seed Oil: Whey Protein Isolate Versus Modified 
Starch, Food Hydrocolloids, 2016; 56, 71-83.

[62] De Barros Fernandes, R.V.; Marques, G.R.; Borges, S.V.; Botrel, D.A. Effect of Solids Content and Oil Load on the Microencapsulation Process of Rosemary Essential Oil, Industrial Crops and Products, 2014; 58, 173-181.

[63] Botrel, D.A.; Borges, S.V.; Fernandes, R.V.D.B.; Lourenço Do Carmo, E. Optimization of Fish Oil Spray Drying Using A Protein: Inulin System, Drying Technology, 2014; 32(3), 279-290.

[64] Klinkesorn, U.; Sophanodora, P.; Chinachoti, P.; Decker, E.A.; McClements, D.J. Characterization of SprayDried Tuna Oil Emulsified in Two-Layered Interfacial Membranes Prepared Using Electrostatic Layer-By-Layer Deposition, Food Research International, 2006; 39(4), 449457.

[65] Roccia, P.; Martínez, M.L.; Llabot, J.M.; Ribotta, P.D. Influence of Spray-Drying Operating Conditions on Sunflower Oil Powder Qualities, Powder Technology, 2014; 254, 307-313.

[66] Laohasongkram, K.; Mahamaktudsanee, T.; Chaiwanichsiri, S. Microencapsulation of Macadamia oil by Spray Drying, Procedia Food Science, 2011;1, 1660-1665.

[67] Ixtaina, V.Y.; Julio, L.M.; Wagner, J.R.; Nolasco, S.M.; Tomás, M.C. Physicochemical Characterization and Stability of Chia Oil Microencapsulated with Sodium Caseinate and Lactose by Spray-Drying, Powder Technology, 2015; 271, 26-34.

[68] Klinkesorn, U.; Sophanodora, P.; Chinachoti, P.; McClements, D.J.; Decker, E.A. Stability of Spray-Dried Tuna Oil Emulsions Encapsulated with Two-Layered Interfacial Membranes, Journal of Agricultural and Food Chemistry, 2005; 53(21), 8365-8371.

[69] Carvalho, A.G.S.; Silva, V.M.; Hubinger, M.D. Microencapsulation by spray drying of emulsified green coffee oil with two-layered membranes, Food Research International, 2014; 61, 236-245.

[70] Escalona-García, L.A.; Pedroza-Islas, R.; Natividad, R.; Rodríguez-Huezo, M.E.; Carrillo-Navas, H.; Pérez-Alonso, C. Oxidation Kinetics and Thermodynamic Analysis of Chia Oil Microencapsulated in A Whey Protein Concentrate-Polysaccharide Matrix, Journal of Food Engineering, 2016; 175, 93-103.

[71] Stapelfeldt, H.; Nielsen, B.R.; Skibsted, L.H. Effect of
Heat Treatment, Water Activity and Storage Temperature on The Oxidative Stability of Whole Milk Powder, International Dairy Journal, 1997; 7(5), 331-339.

[72] Aghbashlo, M.; Mobli, H.; Madadlou, A.; Rafiee, S. The Correlation of Wall Material Composition With Flow Characteristics and Encapsulation Behavior of Fish Oil Emulsion, Food Research International, 2012; 49(1), 379388.

[73] Orlien, V.; Risbo, J.; Rantanen, H.; Skibsted, L.H. Temperature-Dependence of Rate of Oxidation of Rapeseed Oil Encapsulated in A Glassy Food Matrix, Food Chemistry, 2006; 94(1), 37-46.

[74] Thomsen, M.K.; Lauridsen, L.; Skibsted, L.H.; Risbo, J. Two Types of Radicals in Whole Milk Powder. Effect of Lactose Crystallization, Lipid Oxidation, and Browning Reactions, Journal of Agricultural and Food Chemistry, 2005; 53(5), 1805-1811.

[75] Lim, H-K.; Tan, C-P.; Bakar, J.; Ng, S-P. Effects of Different Wall Materials on The Physicochemical Properties and Oxidative Stability of Spray-Dried Microencapsulated Red-Fleshed Pitaya (Hylocereus Polyrhizus) Seed Oil, Food and Bioprocess Technology, 2012; 5(4), 1220-1227.

[76] Omar, K.A.; Shan, L.; Zou, X.; Song, Z.; Wang, X. Effects of Two Emulsifiers on Yield and Storage of Flaxseed Oil Powder by Response Surface Methodology, Pakistan Journal of Nutrition, 2009; 8(9), 1316-1324.

[77] Fang, X.; Shima, M.; Adachi, S. Effects of Drying Conditions on The Oxidation of Linoleic Acid Encapsulated With Gum Arabic by Spray Drying, Food Science and Technology Research, 2005; 11(4), 380-384.

[78] Karaca, A.C.; Low, N.; Nickerson, M. Encapsulation of Flaxseed Oil Using A Benchtop Spray Dryer for Legume Protein-Maltodextrin Microcapsule Preparation, Journal of Agricultural and Food Chemistry, 2013; 61(21), 5148-5155.

[79] Serfert, Y.; Drusch, S.; Schwarz, K. Chemical Stabilisation of Oils Rich in Long-Chain Polyunsaturated Fatty Acids During Homogenisation, Microencapsulation and Storage, Food Chemistry, 2009; 113(4), 1106-1112.

[80] Aghbashlo, M.; Mobli, H.; Madadlou, A.; Rafiee, S. Integrated Optimization of Fish Oil Microencapsulation Process by Spray Drying, Journal of Microencapsulation, 2012; 29(8), 790-804. 
[81] Wang, Y.; Liu, W.; Chen, X.D.; Selomulya, C. Microencapsulation and Stabilization of DHA Containing Fish Oil in Protein-Based Emulsion Through Mono-Disperse Droplet Spray Dryer, Journal of Food Engineering, 2016; 175, 74-84.

[82] Martínez, M.L.; Curti, M.I.; Roccia, P.; Llabot, J.M.; Penci, M.C.; Bodoira, R.M. Oxidative Stability of Walnut (Juglans Regia L.) and Chia (Salvia Hispanica L.) Oils Microencapsulated by Spray Drying, Powder Technology, $2015 ; 270,271-277$.

[83] Dian, N.L.H.M.; Sudin, N.; Yusoff, M.S.A. Characteristics of Microencapsulated Palm-Based Oil as Affected by Type of Wall Material, Journal of the Science of Food and Agriculture, 1996; 70(4), 422-426.

[84] Cluskey, S.M.; Connolly, J.F.; Devery, R.; O’Brien, B.; Kelly, J.; Harrington, D. Lipid and Cholesterol Oxidation in Whole Milk Powder During Processing and Storage, Journal of Food Science, 1997; 62(2), 331-337.

[85] Drusch, S.; Berg, S. Extractable Oil in Microcapsules Prepared by Spray-Drying: Localisation, Determination and impact on Oxidative Stability, Food Chemistry, 2008; 109(1), 17-24.

[86] Ahn, J-H.; Kim Y-P.; Seo, E-M.; Choi, Y-K.; Kim, H-S. Antioxidant Effect of Natural Plant Extracts on the Microencapsulated High Oleic Sunflower Oil, Journal of Food Engineering, 2008; 84(2), 327-334.

[87] Aghbashlo, M.; Mobli, H.; Rafiee, S.; Madadlou, A. Optimization of Emulsification Procedure for Mutual Maximizing the Encapsulation and Exergy Efficiencies of Fish Oil Microencapsulation, Powder Technology, 2012; 225, 107-117.

[88] Kolanowski, W.; Jaworska, D.; Weißbrodt, J.; Kunz, B. Sensory Assessment of Microencapsulated Fish Oil Powder, Journal of the American Oil Chemists' Society, 2007; 84(1), 37-45.

[89] Keogh, M.K.; O'Kennedy, B.T. Milk Fat Microencapsulation Using Whey Proteins, International Dairy Journal, 1999; 9(9), 657-663.

[90] Keogh, M.K.; O'Kennedy, B.T.; Kelly, J.; Auty, M.A.; Kelly, P.M.; Fureby, A.; Haahr, A.-M. Stability to Oxidation of Spray-Dried Fish Oil Powder Microencapsulated Using Milk Ingredients, Journal of Food Science, 2001; 66(2), 217224.
[91] Baik, M-Y.; Suhendro, E.L.; Nawar, W.W.; McClements, D.J.; Decker, E..A.; Chinachoti, P. Effects of Antioxidants and Humidity on the Oxidative Stability of Microencapsulated Fish Oil, Journal of the American Oil Chemists' Society, 2004; 81(4), 355-360.

[92] Vega, C.; Kim, E.H.J.; Chen, X.D.; Roos, Y.H. SolidState Characterization of Spray-Dried Ice Cream Mixes, Colloids and Surfaces B: Biointerfaces, 2005; 45(2), 66-75.

[93] Barbosa-Cánovas, G.V.; Ortega-Rivas, E.; Juliano, P.; Yan, H. Food Powders: Physical Properties, Processing, and Functionality. Springer US: Boston, 2005; pp. 388.

[94] Michailidis, P.A.; Krokida, M.K.; Drying and Dehydration Processes in Food Preservation and Processing. In Conventional and Advanced Food Processing Technologies; Bhattacharya, S., Ed.; John Wiley \& Sons Ltd: Chichester, UK, 2014; pp. 1-32.

[95] Oetjen, G-W.; Haseley, P., Freeze-Drying - Second, Completely Revised Edition; Wiley-VCH Verlag GmbH \& Co. KGaA: Weinheim, Germany, 2008; pp. 407.

[96] Anandharamakrishnan, C., Techniques for Nanoencapsulation of Food Ingredients; Springer New York: New York, 2014; pp. 89.

[97] Heinzelmann, K.; Franke, K.; Jensen, P.; Haahr, A.M. Protection of Fish Oil From Oxidation by Microencapsulation Using Freeze-Drying Techniques, Euroepan Journal of Lipid Science and Technology, 2000; 102(2), 114-121.

[98] Heinzelmann, K.; Franke, K.; Velasco, J.; MärquezRuiz, G. Microencapsulation of Fish Oil by Freeze-Drying Techniques and Influence of Process Parameters on Oxidative Stability During Storage, European Food Research and Technology, 2000; 211(4), 234-239.

[99] Bejrapha, P.; Min, S-G.; Surassmo, S.; Choi, M-J. Physicothermal Properties of Freeze-Dried Fish Oil Nanocapsules Frozen Under Different Conditions, Drying Technology, 2010; 28(4), 481-489.

[100] Na, H-S.; Kim, J-N.; Kim, J-M.; Lee, K-Y. Encapsulation of Fish Oil Using Cyclodextrin and Whey Protein Concentrate, Biotechnology and. Bioprocess Engineering, 2011; 16(6), 1077-1082.

[101] Koç, M.; Yılmazer, M.S.; Kaymak-Ertekin, F. Use of Gelatin, Pullulan, Lactose and Sucrose as Coating Material for Microencapsulation of Fish Oil by Freeze 
Drying, Akademik Gida, 2010; 8(4), 13-16.

[102] Silva, E.K.; Meireles, M.A.A. Influence of the Degree of Inulin Polymerization on the Ultrasound-Assisted Encapsulation of Annatto Seed Oil, Carbohydrate Polymers, 2015; 133, 578-586.

[103] Zhang, Y.; Tan, C.; Abbas, S.; Eric, K.; Zhang, X.; Xia, S. The Effect of Soy Protein Structural Modification on Emulsion Properties and Oxidative Stability of Fish Oil Microcapsules, Colloids and Surfaces B: Biointerfaces, 2014; 120, 63-70.

[104] Karaca, A.C.; Nickerson, M.; Low, N.H. Microcapsule Production Employing Chickpea or Lentil Protein Isolates and Maltodextrin: Physicochemical Properties and Oxidative Protection of Encapsulated Flaxseed Oil, Food Chemistry, 2013; 139(1-4), 448-457.

[105] Turasan, H.; Sahin, S.; Sumnu, G. Encapsulation of Rosemary Essential Oil, LWT - Food Science and Technology, 2015; 64(1), 112-119.

[106] Roos, Y. Characterization of Food Polymers Using State Diagrams, Journal of Food Engineering, 1995; 24(3), 339-360.

[107] Calvo, P.; Castaño, Á.L.; Lozano, M.; GonzálezGómez, D. Influence of the Microencapsulation on the Quality Parameters and Shelf-Life of Extra-Virgin Olive Oil Encapsulated in the Presence of BHT and Different Capsule Wall Components, Food Research International, 2012; 45(1), 256-261.

[108] Calvo, P.; Castaño, Á.L.; Hernández, M.T.; GonzálezGómez, D. Effects of Microcapsule Constitution on the Quality of Microencapsulated Walnut Oil, European Journal of Lipid Science and Technology, 2011; 113(10), 1273-1280.

[109] Imamura, K.; Kimura, Y.; Nakayama, S.; Sayuri, M.; Ogawa, S.; Hoshino, T. Characteristics of Amorphous Matrices Composed of Different Types of Sugars in Encapsulating Emulsion Oil Droplets During FreezeDrying, Food Research International, 2013; 51(1), 201-207.

[110] Karthik, P.; Anandharamakrishnan, C. Microencapsulation of Docosahexaenoic Acid by SprayFreeze-Drying Method and Comparison of Its Stability With Spray-Drying and Freeze-Drying Methods, Food and Bioprocess Technology, 2013; 6(10), 2780-2790.

[111] Grattard, N.; Salaun, F.; Champion, D.; Roudaut, G.;
LeMeste, M. Influence of Physical State and Molecular Mobility of Freeze-Dried Maltodextrin Matrices on the Oxidation Rate of Encapsulated Lipids, Journal of Food Science, 2002; 67(8), 3002-3010.

[112] Anwar, S.H.; Kunz, B. The influence of Drying Methods on the Stabilization of Fish Oil Microcapsules: Comparison of Spray Granulation, Spray Drying, and Freeze Drying, Journal of Food Engineering, 2011; 105(2),367-378.

[113] Silva, K.A.; Coelho, M.A.Z.; Calado, V.M.A.; RochaLeAão, M.H.M. Olive Oil and Lemon Salad Dressing Microencapsulated by Freeze-Drying, LWT - Food Science and Technology, 2013; 50(2), 569-574.

[114] Velasco, J.; Holgado, F.; Dobarganes, C.; MárquezRuiz, G. Influence of Relative Humidity on Oxidation of the Free and Encapsulated Oil Fractions in Freeze-Dried Microencapsulated Oils, Food Research International, 2009; 42(10), 1492-1500.

[115] Minemoto, Y.; Adachi, S.; Matsuno, R. Effect of Relative Humidity During Storage on the Autoxidation of Linoleic Acid Encapsulated With A Polysaccharide by HotAir-Drying and Freeze-Drying, Food Science and Technology Research, 2001; 7(1), 91-93.

[116] Velasco, J.; Dobarganes, M.C.; Márquez-Ruiz, G. Oxidation of Free and Encapsulated Oil Fractions in Dried Microencapsulated Fish Oils, Grasas y Aceites 2000; 51(6), 439-446.

[117] Velasco, J.; Dobarganes, C.; Holgado, F.; MárquezRuiz, G. A Follow-Up Oxidation Study in Dried Microencapsulated Oils Under The Accelerated Conditions of the Rancimat Test, Food Research International, 2009; 42(1), 56-62.

[118] Velasco, J.; Holgado, F.; Dobarganes, C.; MárquezRuiz, G. Antioxidant Activity of Added Phenolic Compounds in Freeze-Dried Microencapsulated Sunflower Oil, Journal of American Oil Chemists' Society, 2009; 86(5), 445-452.

[119] Orlien, V.; Andersen, A.B.; Sinkko, T.; Skibsted, L.H. Hydroperoxide Formation in Rapeseed Oil Encapsulated in A Glassy Food Model as Influenced by Hydrophilic and Lipophilic Radicals, Food Chemistry, 2000; 68(2), 191-199.

[120] Avramenko, N.A.; Chang, C.; Low, N.H.; Nickerson, M.T. Encapsulation of Flaxseed Oil Within Native and Modified Lentil Protein-Based Microcapsules, Food 
Research International, 2016; 81, 17-24.

[121] Dzondo-Gadet, M.; Nzikou, J.M.; Etoumongo, A.; Linder, M.; Desobry, S. Encapsulation and Storage of Safou Pulp Oil in 6 DE Maltodextrins, Process Biochemistry, 2005; 40(1), 265-271.

[122] Minemoto, Y.; Adachi, S.; Matsuno, R. Comparison of Oxidation of Methyl Linoleate Encapsulated with Gum Arabic by Hot-Air-Drying and Freeze-Drying, Journal of Agricultural and Food Chemistry, 1997; 45(12), 4530-4534.

[123] Gouin, S. Microencapsulation: Industrial Appraisal of Existing Technologies and Trends, Trends in Food Science and Technology, 2004; 15(7-8), 330-347.

[124] Wang, X.; Jiang, Y.; Huang, Q.; Encapsulation Technologies for Preserving and Controlling the Release of Enzymes and Phytochemicals. In Encapsulation and Controlled Release Technologies in Food Systems; Lakkis, J.M., Ed.; Blackwell Publishing: Iowa, USA, 2007; pp. 135147.

[125] Wen, J.; Chen, G.; Alany, R.G. Theories and Concepts of Nano Materials, Nano- and microencapsulation. In Nano- and Microencapsulation for Foods; Kwak H-S, Ed.; John Wiley \& Sons Ltd: Chichester, UK, 2014; pp. 15-42.

[126] El Asbahani, A.; Miladi, K.; Badri, W.; Sala, M.; Addi, E.H.A.; Casabianca, H. Essential Oils: From Extraction to Encapsulation, International Journal of Pharmaceutics, 2015; 483(1-2), 220-243.

[127] Devi, N.; Sarmah, M.; Khatun, B.; Maji, T.K. Encapsulation of Active Ingredients in PolysaccharideProtein Complex Coacervates, Advances in Colloid Interface Science, 2017; 239, 136-145.

[128] Aloys, H.; Korma, S.A.; Alice, T.M.; Chantal, N.; Ali, A.H.; Abed, S.M. Microencapsulation by Complex Coacervation: Methods, Techniques, Benefits, and Applications - A Review, American Journal of Food Science and Nutrition Research, 2016; 3(6), 188-192.

[129] Schmitt, C.; Turgeon, S.L. Protein/Polysaccharide Complexes and Coacervates in Food Systems, Advances in Colloid Interface Science, 2011; 167(1-2), 63-70.

[130] Turgeon, S.L.; Schmitt, C.; Sanchez, C. ProteinPolysaccharide Complexes and Coacervates, Current Opinion in Colloid and Interface Science, 2007; 12(4-5), 166-178.
[131] Matsukawa, H.; Katayama, S.; Kiritani, M. Process for Preparing Oil-Containing Microcapsules. US Patent 3970585 A, 1976.

[132] Dong, Z.J.; Touré, A.; Jia, C.S.; Zhang, X.M.; Xu, S.Y. Effect of Processing Parameters on the Formation of Spherical Multinuclear Microcapsules Encapsulating Peppermint Oil By Coacervation, Journal of Microencapsulation, 2007; 24(7), 634-646.

[133] Pothakamury, U.R.; Barbosa-Cánovas, G.V. Fundamental Aspects of Controlled Release in Foods, Trends in Food Science and Technology, 1995; 6(12), 397406.

[134] Kralovec, J.A.; Zhang, S.; Zhang, W.; Barrow, C.J. A Review of the Progress in Enzymatic Concentration and Microencapsulation of Omega-3 Rich Oil From Fish and Microbial Sources, Food Chemistry, 2012;131(2), 639-644.

[135] Tamjidi, F.; Nasirpour, A.; Shahedi, M. Mixture Design Approach for Evaluation of Fish Oil Microencapsulation in Gelatin-Acacia Gum Coacervates, International Journal of Polymeric Materials and Polymeric Biomaterials, 2013; 62(8), 444-449.

[136] Jun-Xia, X.; Hai-Yan, Y.; Jian, Y. Microencapsulation of Sweet Orange Oil by Complex Coacervation With Soybean Protein Isolate/Gum Arabic, Food Chemistry, 2011; 125(4), 1267-1272.

[137] Dong, D.; Qi, Z.; Hua, Y.; Chen, Y.; Kong, X.; Zhang, C. Microencapsulation of Flaxseed Oil by Soya ProteinsGum Arabic Complex Coacervation, International Journal of Food Science and Technology, 2015; 50(8), 1785-1791.

[138] Weinbreck, F.; Minor, M.; de Kruif, C.G. Microencapsulation of Oils Using Whey Protein/Gum Arabic Coacervates, Journal of Microencapsulation, 2004; 21(6), 667-679.

[139] Abdul Aziz, F.R.; Jai, J.; Raslan, R.; Subuki, I. Microencapsulation of Citronella Oil by Complex Coacervation Using Chitosan-Gelatin (B) System: Operating Design, Preparation and Characterization, MATEC Web of Conferences 5th International Conference on Chemical and Process Engineering, 2016; 69, 1-8.

[140] Aziz, S.; Gill, J.; Dutilleul, P.; Neufeld, R.; Kermasha, S. Microencapsulation of Krill Oil Using Complex Coacervation, Journal of Microencapsulation, 2014; 31(8), 774-784. 
[141] Lemetter, C.Y.G.; Meeuse, F.M.; Zuidam, N.J. Control of the Morphology and the Size of Complex Coacervate Microcapsules During Scale-Up, AIChE Journal, 2009; 55(6), 1487-1496.

[142] Dong, Z.; Ma, Y.; Hayat, K.; Jia, C.; Xia, S.; Zhang, X. Morphology and Release Profile of Microcapsules Encapsulating Peppermint Oil by Complex Coacervation, Journal of Food Engineering, 2011; 104(3), 455-460.

[143] Wang, B.; Adhikari, B.; Barrow, C.J. Optimisation of the Microencapsulation of Tuna Oil in Gelatin-Sodium Hexametaphosphate Using Complex Coacervation, Food Chemistry, 2014; 158, 358-365.

[144] Siow, L-F.; Ong, C-S. Effect of $\mathrm{pH}$ on Garlic Oil Encapsulation by Complex Coacervation, Journal of Food Processing and Technology, 2013; 4(1), 1-5.

[145] Martins, I.M.D. Microencapsulation of Thyme Oil by Coacervation: Production, Characterization and Release Evaluation,PhD Thesis, 2012, University of Porto, Portugal.

[146] Eratte, D.; Wang, B.; Dowling, K.; Barrow, C.J.; Adhikari, B.P. Complex Coacervation With Whey Protein Isolate and Gum Arabic for the Microencapsulation of Omega-3 Rich Tuna Oil, Food and Function, 2014; 5(11), 2743-2750.

[147] Wu, K-G.; Xiao, Q. Microencapsulation of Fish Oil By Simple Coacervation of Hydroxypropyl Methylcellulose, Chinese Journal of Chemistry, 2005; 23(11), 1569-1572.

[148] Barrow, C.J.; Nolan, C.; Holub, B.J. Bioequivalence of Encapsulated and Microencapsulated Fish-Oil Supplementation, Journal of Functional Foods, 2009; 1(1), $38-43$.

[149] Patrick, K.E.; Abbas, S.; Lv, Y.; Sandrine, I.; Ntsama, B.; Zhang, X. Microencapsulation by Complex Coacervation of Fish Oil Using Gelatin / SDS / NaCMC. Pakistan Journal of Food Sciences, 2013; 23(1), 17-25.

[150] Dong, Z.J.; Touré, A.; Jia, C.S.; Zhang, X.M.; Xu, S.Y. Effect of Processing Parameters on the Formation of Spherical Multinuclear Microcapsules Encapsulating Peppermint Oil by Coacervation, Journal of Microencapsulation, 2007; 24(7), 634-646.

[151] Pakzad, H. Encapsulation of Peppermint Oil with Arabic Gum-gelatin by Complex Coacervation Method, International Journal of Engineering, 2013; 26(8), 807-814.
[152] Martins, I.M.; Rodrigues, S.N.; Barreiro, F.; Rodrigues, A.E. Microencapsulation of Thyme Oil by Coacervation, Journal of Microencapsulation, 2009; 26(8), 667-675.

[153] Piacentini, E.; Giorno, L.; Dragosavac, M.M.; Vladisavljević, G.T.; Holdich, R.G. Microencapsulation of Oil Droplets Using Cold Water Fish Gelatine/Gum Arabic Complex Coacervation by Membrane Emulsification, Food Research International, 2013; 53(1), 362-372.

[154] Liu, W.L.; Xiao, Z.B.; Zhu, G.Y.; Zhou, R.J.; Wang, E.Q.; Niu, Y.W. Production and Properties of Mononuclear Microcapsules Encapsulating Cinnamon Oil by Complex Coacervation, Applied Mechanics and Materials, 2013; 477-478, 1229-1233.

[155] Dima, C.; Cretu, R.; Alexe, P.; Dima, Ş. Microencapsulation of Coriander Oil Using Complex Coacervation Method, Scientific Study and Research: Chemistry and Chemical Engineering, Biotechnology, Food Industry, 2013; 14(3), 155-162.

[156] Xiao, Z.; Liu, W.; Zhu, G.; Zhou, R.; Niu, Y. Production and Characterization of Multinuclear Microcapsules Encapsulating Lavender Oil by Complex Coacervation, Flavour and Fragrance Journal, 2014; 29(3), 166-172.

[157] Veiga, C.C.; Simoni, R.C.; De Almeida, M.M.C.; Gonçalves, O.H.; Shirai, M.A.; Leimann, F.V. Microencapsulation of Roasted Coffee Oil by Complex Coacervation with Gelatin/Gum Arabic Enzymetically Crosslinked, Brazilian Journal of Food Research, 2016; 7(2), 156-172.

[158] Dong, D.; Qi, Z.; Hua, Y.; Chen, Y.; Kong, X.; Zhang, C. Microencapsulation of Flaxseed Oil by Soya ProteinsGum Arabic Complex Coacervation, International Journal of Food Science and Technology, 2015; 50(8), 1785-1791.

[159] Yari, S.; Nasirpour, A; Fathi, M. Effect of Polymer Concentration And Acidification Time on Olive Oil Microcapsules Obtained by Complex Coacervation, Applied Food Biotechnology, 2016; 3(1), 53-58.

[160] Marfil, P.H.M.; Vasconcelos, F.H.T.; Pontieri, M.H.; Telis, V.R.N. Development and Validation of Analytical Method for Palm Oil Determination in Microcapsules Produced by Complex Coacervation, Quimica Nova, 2016; 39(1), 94-99. 
[161] Zhang, Z.; Pan, M.; Liu, D. Preparation of Microcapsules and Half Life of the Kiwi Fruit Seed Oil by Complex Coacervation, American Journal of Plant Sciences, 2017; 8(2), 191-200.

[162] Sovilj, V.; Milanovic, J.; Katona, J.; Petrovic, L. Preparation of Microcapsules Containing Different Contents of Different Kinds of Oils by A Segregative Coacervation Method and Their Characterization, Journal of the Serbian Chemical Society, 2010; 75(5), 615-627.

[163] Prata, A.S.; Grosso, C.R.F. Influence of the Oil Phase on the Microencapsulation by Complex Coacervation, Journal of the American Oil Chemists' Society, 2015; 92(7), 1063-1072.

[164] Kuhn, K.R.; Silva, F.G.D.E.; Netto, F.M.; da Cunha, R.L. Assessing the Potential of Flaxseed Protein as an Emulsifier Combined with Whey Protein Isolate, Food Research International, 2014; 58, 89-97.

[165] Julio, L.M.; Ixtaina, V.Y.; Fernández, M.A.; Sánchez, R.M.T.; Wagner, J.R.; Nolasco, S.M. Chia Seed Oil-in-Water Emulsions as Potential Delivery Systems of $\omega-3$ Fatty Acids, Journal of Food Engineering, 2015; 162, 48-55.

[166] Fioramonti, S.A.; Martinez, M.J.; Pilosof, A.M.R.; Rubiolo, A.C.; Santiago, LG. Multilayer Emulsions as A Strategy for Linseed Oil Microencapsulation: Effect of $\mathrm{pH}$ and Alginate Concentration, Food Hydrocolloids, 2015; 43, 8-17.

[167] Tamnak, S.; Mirhosseini, H.; Tan, C.P.; Tabatabaee Amid, B.; Kazemi, M.; Hedayatnia, S. Encapsulation
Properties, Release Behavior and Physicochemical Characteristics of Water-in-oil-in-Water (W/O/W) Emulsion Stabilized with Pectin-Pea Protein Isolate Conjugate and Tween 80, Food Hydrocolloids, 2016; 61, 599-608.

[168] Li, X.H.; Yun, J.; Xing, Y.G.; Xiao, Y.; Tang, Y. Complexation of Cinnamon Essential Oil by $\beta$ Cyclodextrin and Its Release Characteristics at High Temperature, Advanced Materials Research, 2010; 146-147, 619-622.

[169] Petrović, G.M.; Stojanović, G.S.; Radulović, N.S. Encapsulation of Cinnamon Oil in $\beta$-Cyclodextrin, Journal of Medicinal Plants Research, 2010; 4(14), 1382-1390.

[170] Shrestha, M.; Ho, T.M.; Bhandari, B.R. Encapsulation of Tea Tree Oil by Amorphous Beta-Cyclodextrin Powder, Food Chemistry, 2017; 221, 1474-1483.

[171] Getachew, A.T.; Chun, B-S. Optimization of Coffee Oil Flavor Encapsulation Using Response Surface Methodology, LWT - Food Science and Technology, 2016; $70,126-134$.

[172] Piornos, J.A.; Burgos-Díaz, C.; Morales, E.; Rubilar, M.; Acevedo, F. Highly Efficient Encapsulation of Linseed Oil into Alginate/Lupin Protein Beads: Optimization of the Emulsion Formulation, Food Hydrocolloids, 2017; 63, 139148.

[173] Freiberger, E.B.; Kaufmann, K.C.; Bona, E.; Hermes de Araújo, P.H.; Sayer, C.; Leimann, F.V. Encapsulation of Roasted Coffee Oil in Biocompatible Nanoparticles, LWT Food Science and Technology, 2015; 64(1), 381-389. 